\title{
Conceptual confusion in the chemistry curriculum: exemplifying the problematic nature of representing chemical concepts as target knowledge
}

\author{
Keith S. Taber ${ }^{1}$ \\ Published online: 26 September 2019 \\ (C) The Author(s) 2019
}

\begin{abstract}
This paper considers the nature of a curriculum as presented in formal curriculum documents, and the inherent difficulties of representing formal disciplinary knowledge in a prescription for teaching and learning. The general points are illustrated by examining aspects of a specific example, taken from the chemistry subject content included in the science programmes of study that are part of the National Curriculum in England (an official document published by the UK government). In particular, it is suggested that some statements in the official curriculum document are problematic if we expect a curriculum to represent canonical disciplinary knowledge in an unambiguous and authentic manner. The paper examines the example of the requirement for English school children to be taught that chemical reactions take place in only three different ways (i.e., proton transfer; electron transfer; electron sharing) and considers how this might be interpreted in terms of canonical chemistry and within the wider context of other curriculum statements, in order to make sense of neutralisation and precipitation reactions. It is argued that although target knowledge that is set out as the focus of teaching and learning cannot be identical to disciplinary knowledge, the English National Curriculum offers a representation of chemistry which distorts and confuses canonical ideas. It is suggested that the process of representing the disciplinary knowledge of chemistry as curriculum specifications is worthy of more scholarly attention.
\end{abstract}

Keywords Chemistry education · Curricular models · Disciplinary knowledge $\cdot$ Canonical concepts $\cdot$ Chemical reactions

\section{Introduction}

This paper examines some of the statements made in the official curriculum document issued by the UK government specifying the chemistry that should be taught in English schools (DFE 2015). It is argued that the way in which chemical knowledge is represented

Keith S. Taber

kst24@cam.ac.uk

1 Faculty of Education, University of Cambridge, 184 Hills Road, Cambridge CB2 8PQ, England, UK 
in this curriculum document is problematic, and that when some of the different statements are juxtaposed they present a confused specification for the teaching and learning being prescribed. This is presented as an example of the challenge of representing canonical chemistry in the curriculum, especially at school level.

To set up this argument, some pertinent background issues are briefly considered. The perspective on the nature of conceptual knowledge assumed in the paper is set out, which has implications for how a text such as a curriculum document (or indeed a scientific paper or a textbook) is understood in relation to the chemical knowledge it represents. Some basic ideas about the nature of a curriculum (including the notion of a spiral curriculum) and how disciplinary knowledge is processed in constructing specifications of target knowledge for teaching are discussed.

In addition, an outline is given for the role of the English National Curriculum document in shaping the teaching of chemistry in the English school system, so to provide readers with the context for the particular examples discussed here. There is no attempt to offer a comprehensive account of the chemistry content prescribed in the English curriculum, but rather some specific statements are examined to highlight problematic issues, and so illuminate the challenge of representing disciplinary knowledge in a curriculum.

\section{The idea of curriculum}

Like many terms in education, 'curriculum' can mean different things (Portelli 1987). Curriculum is taken here to refer to that which is set out as the basis for teaching a particular, identified, group of students. The term is used in a general sense (everything a student is expected to learn 'across' the school curriculum) but is also used in relation to particular courses (e.g., the chemistry curriculum). In broad terms, curriculum can be understood as teaching intentions, and does not need to be set out in documentary form. Indeed, there has been much attention to what is referred to as the hidden curriculum, or perhaps better the implicit curriculum (Cornbleth 1984), which refers to those things that are communicated indirectly and do not appear in any statements of educational aims or teaching schemes. An example might be that teaching that only referred to discoveries made by male chemists, and which used textbooks using illustrations which only showed chemistry being undertaken by men, might communicate an implicit message that chemistry is primarily suitable for males-even if no such claim was ever made in class. Whilst such issues are important, the present paper is concerned with aspects of formal curriculum as set out in official curriculum documents. Further, educational aims may be diverse, and curriculum documents may refer, inter alia, to developing attitudes, and practical skills. Again these aspects are important, but the focus of the present paper is on the way disciplinary knowledge is represented in a teaching curriculum. The discussion here, then, is of aspects of the conceptual content of a chemistry curriculum.

The idea of curriculum applies at different levels, although universities are traditionally autonomous academies that take responsibility for designing their own courses-even if there are some formal mechanisms that encourage a degree of alignment. So, the external examiner system assures a degree of quality control, moderating across universities. Learned societies may offer lists of degree courses they consider meet the expectations for a degree in the discipline-as the Royal Society of Chemistry does (Royal Society of Chemistry 2017). Although Universities traditionally set their own examinations, in the United States some universities buy into the examinations set by the American Chemical 
Society, at least for some of their introductory degree courses (Holme and Murphy 2012). Adoption of an external examination in effect sets out the requirements of that examination as a major part of (if not, in effect) the curriculum for that course.

In school systems there is often a curriculum that is determined externally to the school. Curriculum may be set at various levels. The development of international comparisons that explore (and rank) science learning outcomes across a range of national contexts (Programme for International Student Assessment 2010) may motivate governments to make sure teaching in their jurisdiction suitably prioritises learning likely to lead to desired outcomes in these comparisons. The guidance that national governments may offer on what should be taught, can offer different degrees of flexibility to meet the needs of different groups of students or follow interests locally. The degree to which precise decisions about what should be taught may be delegated to schools and teachers can vary. A national curriculum may specify particular topics and concepts, and set out the level of treatment (as in the example discussed below). Alternatively, a national curriculum might be specified largely in terms of generic outcomes relating to intellectual and other skills, leaving school departments or teachers to select specific content as the medium for developing those skills. Within schools, departments may operate with very structured schemes of work, or may offer individual teachers considerable autonomy.

\section{The process of determining curriculum}

The process of developing a curriculum involves three sets or levels of decisions. These concern scope, selection, and simplification (Taber 2019). In terms of producing a school chemistry curriculum this could be considered to relate to three questions:

(a) Scope; what counts as chemistry? This is about how to identify the disciplinary knowledge that could be potentially included;

(b) Selection: which chemistry? This is a matter of selecting what should be taught from the range of chemical knowledge that could be included.

(c) Simplification: how should the chemistry be represented in the curriculum? In particular, this is a matter of the level of presentation suitable for the learners.

These are all critical matters, and need to be addressed in turn. The focus of the present paper is most closely tied to question (c), so particular attention will be given here to that question, although all three are important.

\section{Potential scope}

Some ideas count as being part of the content of chemistry as a discipline (e.g., redox, lattice enthalpy, aromaticity, etc.) and some do not (alleles, electromagnetic induction, social class). Reaction kinetics and heterocyclic organic compounds would likely be included as topics that make up part of the remit of chemistry, whilst food chains and the poetry of T. S Elliot would likely be excluded. Chemistry as a bounded area of activity is socially constructed. This is true despite the study of substances and their interactions being a focus well-motivated by what is observed in the natural world, as our parsing of academic disciplines is somewhat contingent and not logically necessary. So, if there are scientists on other planets elsewhere in the universe it is possible they may not consider chemistry and physics (as we conceive them) as different sciences, and if they do, they may well conceive 
the boundary between them somewhat differently than has become conventionally accepted on earth (perhaps avoiding the overlap in activity sometimes found between work in chemical physics in physics departments and aspects of physical chemistry in chemistry departments). The extent to which biochemistry may be seen as a distinct discipline to be located in a separate university department, rather than as a division of chemistry, is not a necessary consequence of the nature of the subject matter, but clearly is influenced by local political considerations. Given how diverse chemistry is as a discipline, it is not difficult to imagine that under different historical circumstances a discipline could have evolved which includes what we think of as chemistry, or major divisions of it, and also what is usually considered today to fall under pharmacology or geology. Perhaps, somewhere in the universe, students study a science subject which we would consider as a combination of organic chemistry, biochemistry, genetics, and pharmacology; and another that we would recognise as inorganic and physical chemistry plus geology and mineralogy.

Despite this, there is broad agreement (that is, here on earth, today) on what content is usually included within chemistry as a curriculum subject. It has been argued that curriculum subjects vary in the extent to which they have clear boundaries (Sikoyo and Jacklin 2009) and chemistry would generally be considered a subject where there is 'strong classification' (Bernstein and Solomon 1999), such that boundaries between chemistry and other disciplines, or indeed between disciplinary chemical knowledge and vernacular folk knowledge, are relatively clear. That is, there is likely to be general agreement over what counts as chemistry and what does not.

I am leaving aside some important arguments here about the extent to which science subjects should be taught through placing the science within strong societal contexts (McConnell 1982), and through discussion of socio-scientific issues (Zeidler 2014). This can require teaching that draws on other disciplines (e.g., economics, social science) as well as chemistry. These discussions go beyond arguments about teaching chemistry in context largely as a means of making the subject seem relevant to many students who may not be inherently interested in studying chemistry (Eilks and Hofstein 2015). That (i.e., teaching chemistry through contexts) can be achieved by decisions about how to frame and teach the chemistry content identified and selected for inclusion in the curriculum. Rather, the argument for focusing on socio-scientific issues links to the wider purposes of education, and the role of chemistry as a curriculum subject in the education of all childrengiven that the majority will not seek to study chemistry in higher education or enter chemically-based careers (Millar and Osborne 1998). Education in chemistry that supports the development of the future citizen of a technologically advanced democracy; that provides educational experiences that will support learners in preparing for future decision-making as consumers, as patients in health care, as actors in the environment; may indicate that the subject matter of chemistry should be seen more widely than in terms of topics and concepts. There is also a strong argument that the challenges of learning about such issues, and teaching with a focus on the nature of science, may, by requiring students to engage with questions with no clear definite answers, support intellectual development (Taber 2016).

Despite the importance of these questions, for this paper I am considering the conceptual content of chemistry to be understood in terms of the concepts, theories, models, and so forth, that are usually studied under topic headings such as acids and bases; the periodic table; thermodynamics, etcetera. 


\section{Selection}

If the content of chemistry as an academic discipline is considered to be represented in the research literature that is considered to fall within the scope of chemistry (a point returned to below), then there is certainly a great deal of it. There is clearly more chemistry reported than could be effectively included in an honours degree programme in chemistry, and certainly more than can reasonably be included in a school chemistry course. Therefore, there has to be selection of material. Even if it were possible to agree on including something from all main chemistry topics or themes (assuming there is a consensus on what these are) it is clearly not possible, even if anyone were to think it desirable, to discuss the findings of every published study - to include every known example of all kinds of reactions, or every reported chemical or physical property of an element or compound reported in the literature; or every conjectured reaction mechanism; or every suggested preferred form of the periodic table, and so forth. Clearly there has to be selection of the material judged most important or relevant for a group of learners.

\section{Simplification}

Perhaps in a degree course there might be an argument that this process can stop at selection, as once it is decided what should be included then students should be able to engage with the chemistry at the level of the research scientists reporting the work. This might apply to some undergraduates in relation to some of the literature, but even in university teaching it is likely that much selected material will best be framed in a form that is different from its presentation in the research literature itself. There may be a good case for asking students to appreciate some canonical scientific ideas in the context of how they came to be proposed and tested, and reported as knowledge claims initially motivated as science in the making (Shapin 1992) or science in action (Latour 1987). Yet, it is likely unmanageable to base a coherent chemistry curriculum with broad coverage in those terms: some case studies presenting chemical knowledge contextualised as first presented within an unfolding research programme will likely be valuable, but more usually specific findings need to be decontexualised from their original studies, and represented as part of a synthesis of knowledge about a particular topic. Chemistry, as a science, is a dynamic venture that progresses by an iterative cycle of theoretical and empirical increments that slowly and subtly shift understandings among a community of researchers, unlike the kinds of ossified and definitive statements of knowledge commonly found in textbooks (Taber 2019) and considered suitable as target knowledge for novices.

The issue is clearer when school curriculum is considered. If school students were taught chemical knowledge in the form in which it was first presented in the literature, and in the context of the original studies, then most students would make little of it. Chemistry is a highly conceptual subject with a high density of abstract ideas, and it draws heavily on explanations in terms of an invisible, conjectured, submicroscopic realm of unfamiliar entities (Taber 2013c). This makes it challenging for many students even when teaching takes account of the students' starting points.

So chemistry, in the sense of the content of the academic discipline, will not appear in a school chemistry curriculum. Rather, it will be represented. What is taught is a version of chemistry considered suitable for learners of a particular age, taking into account their intellectual development and prior background learning. This requires simplification 
of content. The school chemistry curriculum offers what might be described as a set of curricular models of chemistry disciplinary content: reconstructed (or perhaps even deconstructed) versions of chemical concepts, theories, scientific models, etcetera. So, simplifying conceptual material to make it suitable for learning is a core and necessary part of the educational process (Taber 2013b), and that principle is certainly not being criticised in this paper. Clearly, however, there are judgements to be made in representing academic content in the curriculum, and in this paper I do raise questions about some of the specific choices made in the English National Curriculum.

\section{Theoretical perspective}

The perspective informing the present paper is a form of constructivism, sometimes termed pedagogic or psychological constructivism (Taber 2009b). This is informed by work in the learning sciences which explores the means by which people come to knowledge. Terms take their meanings within particular frameworks, and knowledge here is not used in the traditional sense of true, justified, belief (Bhaskar 1981)—which arguably only allows someone to judge what is taken as knowledge if they themselves can adjudicate what is true. Scientific knowledge is often considered to have a conjectural nature, such that we always accept the possibility of being mistaken, and consider knowledge provisional in the sense that it is open to re-examination in the light of new evidence or new ways of thinking about existing evidence. Within educational contexts, such as when exploring student learning, a focus on true, justified, belief is not especially useful, given that (as seen above) target 'knowledge' is itself often a simplification and seldom 'the whole truth'. So 'knowledge' is used here more in the sense of those notions that a person is currently entertaining as possibly the case (Taber 2013b). This admits the possibility of considering alternative contradictory notions as knowledge (in this sense of the word), and this is not considered problematic in relation to this definition of knowledge as long as the 'knower' does not confidently commit to several contrary ideas. Research suggests that people's knowledge (when this term is used in the sense adopted here) is often manifold, and multifaceted (Mortimer and El-Hani 2014; Taber 2000b), and may be applied differentially according to contexts (Palmer 1997). Conceptual change, in both scientists and students, often involves the consideration, as possibly the case, of material which is not consistent with what has to that point been considered likely (or even, given human nature, definitely) the case (Thagard 1992). Whilst this use of the term 'knowledge' is defended on the grounds of its fit with the nature of human cognition, the arguments made in this paper are not damaged by a rejection of the present use of the descriptor 'knowledge' (that is, what I am calling knowledge could just be described by another term for labelling the set of ideas a person currently entertains as possibly being the case).

It is also assumed here that conceptual knowledge only exists where there is a conceiver. Concepts exist in minds, rather than in some Platonic third world of ideas (Popper 1979), although such idealisations of concepts with independent existence are useful referents (that is, useful fictions). If sentient life on earth were extinguished, there would be no chemical concepts here. This is not an argument about ontology (except in relation to the nature of concepts themselves): the world would carry on existing, and continue to contain substances (or mostly mixtures and composites) that would not change their natural properties. If plants survived this hypothetical extinction event, then photosynthesis would continue, but the concept of photosynthesis requires someone to conceive 
of the process as photosynthesis, so the concept would no longer exist. Concepts are mental entities, so-called World 2 entities (Popper 1979), and require mental activity to be subjectively accessed.

This hypothetical post-extinction world may contain books and journals and laboratory notebooks and computer files with webpages, podcasts, videos of chemistry talks and demonstrations. These are all representations of people's knowledge, but none of them contain knowledge. Rather, people have to find ways to represent their knowledge that others can understand. Others can develop their own knowledge from such resources, but this is not an automatic, assured process: rather the learners do so by interpreting the representations, which requires appropriate language, and sufficient prior knowledge for the representations to be meaningful (Ausubel 2000). Language here includes specialised symbolic systems where these are used for representation, so chemical formulae for example (Taber 2009a) in the case of interpreting representations of chemical knowledge. Communication of knowledge may be effective, in the sense that one person represents their ideas in ways that allow another person to acquire pretty much the 'same' ideas, but the process is not guaranteed, and is prone to errors (failures to understand, misinterpretation). For most teachers, especially those working at school level, this last point is not a theoretical consideration, but a mainstay of professional experience.

The research paper contains a representation of some particular knowledge claims supported by an argument informed by some specific data framed and presented as evidence (Medawar 1963/1990). Another scientist in the same field will likely be able to develop an understanding of the claims made, and the justification for them, that is a close match to what the authors intended to communicate. A scientist with a very different area of specialisation, or an undergraduate of the discipline, would likely form a more partial understanding. A school student would typically struggle to make good sense of a paper in a chemistry research journal, even if they had studied the general topic in which it might be considered to fall, and so might be doing well to develop a vague notion of the argument being made. A review article might be more accessible, at least for the undergraduate, but relies on the author undertaking a good deal of intellectual work of selecting, organising, and representing their own interpretations of the primary sources. Most school students would still struggle to make good sense of such an article. A textbook written for a school chemistry course would hopefully present text that is accessible and meaningful (and engaging) for the target population of students: but would involve the author representing their own understanding of the science in a form that loses much of the detail and simplifies many of the ideas. Even then, the text represents rather than contains knowledge: a reader cannot extract or copy knowledge from the book, but rather has to interpret and make sense of the text and graphic representations in terms of their existing knowledge and understanding. This is not to suggest that humans cannot be very skilled in communicating effectively (Bruner 1987), or that barriers to understanding another's ideas are insurmountable (Popper 1994). However, there is always the risk that flaws in a learner's prior knowledge, or limitations in language comprehension or visual literacy (when viewing figures) may lead to misinterpretations, and so to alternative conceptions of the chemistry (Gilbert and Watts 1983; Taber 2015) that do not match what the author intended.

These arguments are developed in more detail elsewhere (Taber 2013b, 2019). I do not consider them essential to appreciating the criticism I present below of the ENC document-as I suspect that chemists who are not convinced by the perspective I adopt would 
still agree that the curriculum features I discuss below are problematic — but they underpin the way in which I frame the presentation.

\section{The spiral curriculum}

Many school curricula are intended to reflect what is known as a spiral curriculum. This notion was popularised by the educational theorist Jerome Bruner (1960). Bruner was working at a time when Jean Piaget's theory of cognitive development, genetic epistemology as he called it (Piaget 1970/1972), was very influential in science education (Bliss 1993) with its assumption of a set sequence of levels of cognitive development that all normally developing people pass through. Under Piaget's scheme, children needed to reach what was termed the level of formal operational thinking before being ready to cope with abstract theoretical ideas - of the kind that populate school chemistry courses (such as oxidation, rate of reaction, neutralisation, electronegativity, chemical bond, etc.). As it was known from surveys that learners normally only developed this level of thinking during adolescence, it was suggested that there was a severe mismatch between the content of school science curriculum, and the learning many students were ready to undertake (Shayer and Adey 1981).

In this context Bruner made an extraordinary claim: that "any subject could be taught effectively, in some intellectually honest way to any child, at any stage of development" (1960, p. 33). If taken at face value, Bruner was claiming that it would be possible to effectively teach a five year old, say, the essence of quantum mechanics or natural selection or general relativity. He was not claiming the child could be taught to understand the ideas in the way a graduate student might, but that it was possible to offer a simplification that reflected in some meaningful sense the core of the scholarly idea. The requirement that this should be intellectually honest meant that it was not acceptable to use a simplification or analogy that satisfied the child but distorted the idea to such an extent that it no longer authentically reflected the source concept. The claim may have been overstated, but it was seen as aspirational in encouraging teachers to find ways to help learners engage with ideas that they were not ready to tackle at their full level of sophistication.

A spiral curriculum is designed such that learners will revisit areas of knowledge over time. As they mature they should meet increasingly sophisticated treatments of a topic, with increasing abstraction and nuance. This principle is reflected in recent work looking to design what are called 'learning progressions' (Shavelson and Kurpius 2012). As with a spiral staircase, early steps are the means of making progress to the higher levels. In designing such a curriculum, each time students meet a topic area they should be building upon what they have learnt before, and developing the foundations for later more advanced learning.

From this perspective, a curricular model-the prescribed treatment of a topic or concept for a particular group of learners - needs to reflect the optimum level of simplification (Taber 2000a). There should be sufficient simplification for students to access and engage with the ideas, whilst avoiding over-simplification that might act as a barrier to further learning. For example, consider the topic of atomic structure. For students of a certain age, it may be perfectly sensible to present an atomic model in terms of concentric shells of electrons around the nucleus, as long as (a) students have learnt about the nature of models, and (b) it is presented explicitly as a model, and so students do not consider this an absolute final scientific account of how one feature [aspect] of the world is (Taber 2010). A 
shell-based model can be a step towards a more sophisticated model, or a barrier to learning a more sophisticated model, depending on the presentation.

Secondary school students can only be taught about a limited range of chemistry in any detail. In considering atomic structure, students may, for example, apply the shell model to the first 20 elements. They may be taught that octet outer shell configurations are very common in the compounds of these elements. That is reasonable. However what is often learnt (i.e., how students interpret teaching, and what indeed is actually found in some school text books) is that the second and third electron shells become full at eight electrons. They may at this time only meet examples where this is indeed so. Yet, this is not only clearly incorrect, but causes difficulty for those who progress to advanced courses where they are taught about compounds of $\mathrm{P}, \mathrm{S}$, and $\mathrm{Cl}$, where the third shell is not restricted to 8 electrons. Over-simplification distorts the science, impedes further learning, and may frustrate students when they are later asked to learn something that seems to contradict what they have previously been taught. Determining what counts as an optimal level of simplification, and so a suitable curricular model, is in part a philosophical question (determining what counts as an authentic simplification that retains the essence of the canonical concept) and in part an empirical one (finding what students of particular ages, having already mastered specific prerequisite learning, can meaningfully engage with, and learn, without distorting the intended meaning).

\section{The spectre of canonical concepts}

The term canonical concepts refers to those concepts that have wide currency within the relevant community - say here the community of professional chemists (however defined). In considering the curricular models that may be posited in a particular educational context we can judge them authentic if we consider they are suitable simplifications of canonical knowledge. Yet the astute reader may reasonably cry 'foul' here. I have suggested above that concepts are mental entities that only exist in the minds of people and can only be imperfectly represented in texts; and that the communication of concepts is open to error as each person has to interpret new learning in the light of their existing knowledge and understanding. The literature is vast, and much of it is no longer current in the sense that the knowledge claims in journal papers have often, since their publication, been refuted, or become refined by further work, or have ceased to be seen as offering a productive understanding of the topic. Even the chemistry literature that is current (if we could agree precisely what that was) is vast and not always consistent. It includes ideas that are widely accepted and applied, and contributions that are seen as more tentative, some of which will in time become more widely accepted, whilst others drop from view.

As texts are in any case only representations of knowledge, and concepts are mental entities, then perhaps canonical concepts could better be understood as the versions of concepts that a particular academic community, here chemists, currently holds. Yet even if we could identify 'the community of chemists' (and if we [sic] ask who is the 'we' who gets to decide this, we likely end up with either a tautological criterion - the community of chemists decides who is in the community-or an infinite regress, as someone has to decide who should decide who counts as a chemist for this purpose, and so on), and survey the community, there would not be a common set of concepts agreed by all: there would be at least nuanced differences in how acidity or oxidation or atomic orbitals were understood (related to issues of how defined, ontological status, range of application across contexts, etc.) 
I am suggesting there are no canonical concepts as such-rather, usually there is widespread agreement, among most chemists who would claim to know about a topic area, about the general nature of the key ideas. That is usually good enough for most purposes, whilst leaving enough intellectual space for genuine disagreements between different chemists about what should be counted as canonical knowledge in some areas of the discipline (Scerri 1989). I therefore fall back upon referring to canonical concepts, as this notion of canonical concepts does useful work even if the commonalities the community actually share in their thinking are often a little weaker and more diffuse than would be the case if they shared genuinely canonical concepts. Entities do not have to be real to have effects. Or rather, the idea of something that is not real can have effects. Military action may be started on the basis of inaccurate reports of weapons hidden in a desert. Many parents have moderated their children's behaviour using the idea of Father Christmas visiting, and thousands of European women were put to death after the Reformation because of the idea of witches.

Canonical chemical concepts may not strictly exist, but the idea that they can be identified is a useful fiction (Taber 2019). The practice of teaching a subject such as chemistry, where students are assessed according to how well they master 'the' concepts and principles of the discipline, depends upon some arbitration of what counts as chemically 'correct'. The chemistry education community generally behaves as if we can all agree on what counts as chemical knowledge in order to use that as a referent in constructing curricular models. Much of the time that pretence works fine-although occasionally there are disagreements between teachers that cannot be resolved when it proves difficult to demonstrate what is canonical. So we might imagine one teacher being convinced that it is correct to describe an atom of argon as a molecule, whilst another is just as convinced that this would be non-canonical, and an attempt to find out who 'is right' reveals contradictions between different sources expected to be authoritative. As these cases tend to be the exceptions, chemistry educators largely carry on as if it is possible to find out, and agree, precisely what canonical chemical knowledge currently is. (The extent to which different teachers may be inadvertently teaching inconsistent versions of the 'same' concept, whilst assuming their practice is reflected among colleagues, is an intriguing empirical question.) The process of taking canonical chemical concepts as referents for constructing curricular models is then, strictly, flawed (if in principle there are no unambiguously canonical concepts, and no clear uncontested authoritative source that could be relied on to check candidates for such referents), but has heuristic value as most of the time it works well enough given what is taken for canonical knowledge. Indeed the logical incompleteness of the process may only become clear when contested examples are highlighted. Below I contest a statement presented as a curricular model of chemical knowledge by the UK's government department responsible for setting the school curriculum.

\section{The English National Curriculum}

England is one of the constitutive countries of the United Kingdom of Great Britain and Northern Ireland (UK). It has had a National Curriculum for almost thirty years (Statutory Instrument 1989), that has been subject to various major and minor revisions, some of which have been subject to vigorous debate (Gilland 2006). That debate tends to be over broad issues of coverage, rigour, organisation, and so forth, rather then the specifics of individual specified statements of target knowledge. The English National 
Curriculum (ENC) is divided not only in terms of subjects, but also in terms of student age. The terminology of 'Key Stages' (KS) is used with KS1 being for 5-7 year old children (Years 1-2); KS2: 7-9 year-olds (Y3-6); KS3: 11-14 year-olds (Y7-9); and KS4: 14-16 year-olds (Y10-11). Dividing the curriculum up in this way supports the use of the principle of a spiral curriculum (as considered above) that requires students to revisit some of the same topics and ideas at different levels of treatment as they progress through their school careers. Students take national examinations at age 16 across a spread of subjects. Science is a compulsory subject in the curriculum, and although chemistry does not formally appear as a school curriculum subject (Taber 2006) it is recognised as a section in the current version of the science curriculum (and was explicit, or more often implicit, in earlier versions) that is meant to offer a broad and balanced science experience.

When it was first introduced, the ENC was compulsory in state schools (attended by about $93 \%$ of school age children) in England, so that all students in those schools, apart from some special exempt cases, had to study science to age 16. In recent years there has been some turmoil in the state school system with attempts to introduce a range of new types of school (relating more to issues of governance and accountability than pedagogy or curriculum) such that some state schools are now technically exempt from having the teach the ENC. However, the national examinations taken by nearly all 16 years olds are set by a small number of examination boards under the oversight of an official curriculum and assessment authority that approves their examination specifications (Ofqual 2015a, b), so that even if a school is not legally required to apply the ENC, their students will usually take examinations that must align with the ENC requirements. In effect, then, this is a prescribed curriculum.

It was suggested above that a formal curriculum presents representations of scientific knowledge following processes of scoping, selecting, and simplifying. Curriculum documents are intended primarily for teachers, and often there will be further stages of processing of curriculum content before it is presented to students: that is, teachers will need to interpret the intentions of curriculum statements (in the light of their own understanding of content) and decide how to represent this in teaching. Sometimes this may require further simplifications (or decisions to extend beyond the prescribed content), and may involve the use of pedagogic devices such as teaching models, analogies, similes, and even anthropomorphic narratives (e.g., "an atom wants a full shell of electrons"). These representations of the curriculum specifications are one step further from the original scientific accounts found in the primary disciplinary literature (Taber 2019).

In the ENC context there has been a tendency to supplement and augment official curriculum documents with other related guidance of various kinds, either produced by the government department itself or one of a number of quangos (quasi-governmental organisations) related to curriculum and assessment (for a critical account, see Taber 2018). There have been frequent changes in statutory requirements, non-statutory guidance, and indeed the relevant authorities themselves.

For example, a previous version of the KS3 science curriculum (for 11-14 year old learners) was augmented by a suggested model teaching scheme published by the Qualifications and Curriculum Authority (e.g., QCA 2000), and then an extensive initiative (a 'National Strategy') offering pedagogic guidance and including a detailed framework discussing how the curriculum content could be sequenced and linked (Key Stage 3 National Strategy 2002). At KS4 (for 14-16 year olds), which is the main focus of this article, teachers tend to give priority in their planning to the examination specifications for the most common examinations taken by 16 year olds-known as 'GCSEs' (subject awards credited 
in the General Certificate of Secondary Education). Most students in England follow a balanced science course (currently known as Combined Science) that leads to a certification credited as two examination subjects, but some students take three discrete science subjects certified as Biology, Chemistry, and Physics, and requiring study of additional material beyond that required for the double award.

In England the GCSE examinations are set by examination boards independent of the government. There are three boards based in England, two charitable bodies-know as OCR and AQA - and a division of a multinational corporation (Edexcel, part of Pearson Education). Each of these Boards can offer their own distinctive versions of GCSE science and GCSE chemistry examinations. There is also an Examination Board in Wales, WJEC, which as well as offering services to Welsh Schools based on examination specifications approved by the Welsh national qualifications authority (Qualifications Wales), also has a division (Eduqas) offering examination services to English schools based on specifications approved by the English qualifications authority (Ofqual).

Moreover, rather than simply expecting examination boards to be guided by the NC itself, the government or its agency issue guidelines on the subject content criteria that GCSE examinations must include (DFE 2014a; Ofqual 2015a, b). Consequently, 14-16 year old students follow a variety of examination courses in science or chemistry, each of which is required to meet subject criteria, which are themselves required to be consistent with the ENC document (DFE 2015). The present article focuses primarily on the representation of chemistry in the ENC document itself, which is the primary prescription of what school children should be taught.

The statements examined below are taken from a document entitled 'National curriculum in England: science programmes of study' (DFE 2015), described as having the status of Statutory Guidance, 'updated' 6 May 2015, and appearing on the website of the Department for Education, a department of the UK National Government. Unhelpfully, when referring to parts of the curriculum document for purposes of critique, the document does not include pages, numbered sections, or numbered paragraphs. As a government document there is no specified author or listing of those who contributed to conceptualising, writing, editing, or checking, the curriculum specification. I wish here in particular to draw attention to some of the statements in the section entitled 'Subject content-Chemistry' for KS4 (that is, 14-16 year-olds). The planned content of the school leaving science examination was initially published in draft (DFE 2014a) a year before the finalised document, and very quickly amended when it was found to contain errors in physics formulae included (that "kinetic energy $=0.5 \times$ mass $\times(\text { acceleration })^{2}$ ", where 'acceleration' should be 'velocity', and "(final velocity $)^{2}$ - (initial velocity $)^{2}=2 \times$ acceleration $\times$ time" where 'time' should be 'distance', p. 35). A draft of the curriculum specification for the KS4 stage of the teaching curriculum was then published (DFE 2014b).

\section{A curriculum model of reaction mechanisms}

Students of this age (14-16 year olds) do not study formal reaction mechanisms as tend to be represented with curly arrows (or fishhooks). However, one of the statements set out as target knowledge is:

"chemical reactions take place in only three different ways: 
- proton transfer

- electron transfer

- electron sharing"

This is immediately followed by the statement that

- "energy is conserved in chemical reactions so can therefore be neither created nor destroyed"

That last bullet point ("energy is conserved in chemical reactions so can therefore be neither created nor destroyed") is logically unsound. Accepting that "energy is conserved in chemical reactions" does not imply ('therefore') that energy can "be neither created nor destroyed" as it tells us nothing about what may happen in collisions, or when objects absorb radiation, or when there is a change of state, or when a hot object cools, etcetera. This statement was unchanged from the published draft (DFE 2014b), and despite criticism of the wording appearing in a blog published by the Royal Society of Chemistry (Taber 2014), was retained in the updated version published the following year (DFE 2015), which is the current version on the UK government website at the time of writing this article (mid-2018). Any document can include errors, but this logical howler has-at the time of writing this paper-been allowed to stand as something children should be taught for over three years. This same wording ("energy is conserved in chemical reactions so can therefore be neither created or destroyed") is also found in the GCSE subject content specification for combined science (Ofqual 2015a, p. 18) and in the chemistry section of the requirements for GCSE courses in the separate sciences (Ofqual 2015b, p. 20). Indeed, the wording is reproduced without correction in examination specifications issued to teachers by the examination boards (AQA 2016, p. 83; Edexcel 2018, p. 6; Eduqas 2019, p. 7; OCR 2019, p. 11). Moreover, a quick web-search found the this precise wording appears on the public websites of a range of schools, as part of the curriculum information provided for children and their parents. ${ }^{1}$ Whether the initial mistake was due to a genuine conceptual confusion, or a simple slip in producing the draft text, the erroneous formulation survived, without correction, the revision of the draft curriculum document, and adoption into, first, the examination specification criteria, and, then, into the examination specifications themselves, and even into school teaching schemes. It is as if once a statement is reified in an official curriculum document, it is reproduced in fidelity as though it is a slogan to be adopted as a creed, rather than something to be critically thought about, and understood.

\section{An exclusive typology of types of reaction mechanism}

Leaving this embarrassing error aside, I would like to consider whether the rest of this statement reflects canonical chemical knowledge. I will pose the question: is the statement that "chemical reactions take place in only three different ways: proton transfer; electron transfer; electron sharing" canonical-that is, is it an authentic reflection of current

\footnotetext{
1 As of 18th May 2019, a search with the Google search engine led to public webpages with this wording on the sites of Al-Ashraf Secondary School for Girls, Gloucester; John Cabot Academy, Bristol; Kensington Aldridge Academy, London; Manor School Sports College, Northamptonshire; Matthew Moss High School, Rochdale; Rugby Free Secondary School, Warwickshire; Sir Charles Kao University Technical College, Harlow; St Andrew's CE School, Croydon; Westfield Secondary School, Sheffield.
} 
chemical knowledge? Again, this wording in the curriculum document ("chemical reactions take place in only three different ways: proton transfer[,] electron transfer[,] electron sharing") is repeated in the documents setting out the content that must appear in the specifications for the GCSE examinations in combined science (Ofqual 2015a, p. 18) or chemistry (Ofqual 2015b, p. 20). And, again, this wording is also reproduced in the specifications provided by the Examination Boards for English schools (AQA 2016, p. 83; Edexcel 2018, p. 6; Eduqas 2019, p. 7; OCR 2019, p. 11). In particular, I would like to focus on the use of 'only' suggesting this is an exclusive statement: one that covers all chemical reactions.

I think it is reasonable to do some rephrasing which retains (my understanding of) the meaning of this statement, to give: all chemical reactions take place by proton transfer; and/or electron transfer; and/or electron sharing. This would suggest we can logically deduce that any process that does not take place by proton transfer; and/or electron transfer; and/or electron sharing is not considered to be a chemical reaction.

Yet there would seem to be exceptions: I can immediately think of two related classes of reaction. There are precipitation reactions, such as the formation of lead iodide by mixing solutions of potassium iodide and lead nitrate (and many others such as those analytical tests relying on the low solubility of silver chloride and barium sulphate). There are also neutralisation reactions. A common school practical produces crystals of sodium chloride by neutralising hydrochloric acid with sodium hydroxide and evaporating the solvent (water). I wish to ask: How might we make sense of these examples in relation to the model of reaction mechanisms presented in the ENC?

\section{Interpreting proton transfer, electron transfer, and electron sharing}

It is argued here that although it is possible to discuss all reaction mechanism, including precipitation reactions, in terms of shifts in distributions of electron charge density relative to atomic nuclei, the level of treatment presented in the ENC clearly suggests a less sophisticated interpretation of terms such as electron transfer and electron sharing. It is also argued that whilst it is possible to fit neutralisation reactions under the scheme 'proton transfer; and/or electron transfer; and/or electron sharing', such an interpretation relies upon a problematic treatment of one of chemistry's key concepts: chemical reactions.

\section{Precipitation reactions}

We could argue that when lead iodide precipitates from solution, ions lose their hydration shells and form a crystal lattice, and this involves shifts in electron density distributions which could be considered a subtle form of electron transfer or sharing. Such conceptualisations are not completely unreasonable-but it seems pretty clear from the level of treatment of the chemistry in the ENC that this kind of subtle argument is not the level of understanding that is intended. This is a matter of interpretation, of course (the text is only a representation of knowledge), but a search of the document did not find any use of terms which could suggest such a nuanced treatment was expected: terms such as electron cloud, electron density, electron distribution, dipole, hydration, orbital, polar, polarisation, solvation. So teachers are not being asked to explain how precipitation can be understood to be a kind of shift in the electron distribution around the ions as they form into a lattice. At the level of sophistication of the concepts and statements specified, a precipitation reaction does not involve proton transfer or electron transfer or electron sharing. 
Another response might be that the problem with the wording is that it is a little too definitive ("chemical reactions take place in only three different ways"-emphasis added), and what is meant is that all chemical reactions studied in the ENC take place by proton transfer; and/or electron transfer; and/or electron sharing. As suggested above, a curriculum model needs to simplify the complexity of the disciplinary knowledge. No school curriculum can ask pupils to study all known chemical reactions, and so there might be an argument for excluding some classes of reactions - which students might then go on to meet if they study the subject further after completing this level of study. This is a defensible approach that could be taken, although neutralisation reactions and precipitation reactions (sometimes called double decomposition reactions) have traditionally been taught at this level. Traditions are not necessarily worth keeping, so we might perhaps wonder if the ENC excludes these classes of reaction from study.

\section{Neutralisation reactions}

Yet another section of the ENC KS4 Chemistry subject content requires students to learn "the chemistry of acids; reactions with some metals and carbonates", but it seems acid-base reactions are not specified for study by 14-16 year-old students in English schools. However, the KS3 chemistry specification (i.e. specifying material that would have been studied by 11-14 year-old students, earlier in their schooling) has a section entitled 'chemical reactions' that includes, among others, the following two bullet points

- "defining acids and alkalis in terms of neutralisation reactions"

- "reactions of acids with alkalis to produce a salt plus water"

It seems therefore that knowledge of acid-base neutralisation reactions is expected as prior knowledge for the students who are to be taught that "chemical reactions take place in only three different ways: proton transfer; electron transfer; electron sharing".

In the case of the acid-base reaction we could argue that the real reaction is less the production of the sodium chloride than the formation of water molecules from hydrogen ions (protons) and hydroxyl ions, which can be seen as the donation of protons and/or electrons. The curriculum document itself makes no mention of hydroxyl ions (although it does specify " $\mathrm{pH}$ as a measure of hydrogen ion concentration"). This interpretation is, however, adopted in the documents setting out requirements for the GCSE awards in combined science or chemistry, where students are to be expected to "recall that acids form hydrogen ions when they dissolve in water and solutions of alkalis contain hydroxide ions" and to "recognise that aqueous neutralisation reactions can be generalised to hydrogen ions reacting with hydroxide ions to form water" (DFE 2014a, pp. 21-22; Ofqual 2015b, p. 24).

It seems, then, that in moving from the curriculum itself, to the requirements given to examination boards for preparing examination courses, there has been an interpretation and elaboration for how neutralisation reactions between acids and alkalis should be understood (to fit with the curriculum statement on reaction mechanisms) that goes beyond the curriculum specification itself. The idea that "aqueous neutralisation reactions can be generalised to hydrogen ions reacting with hydroxide ions to form water" is quite sophisticated, and whether it is appropriate for this to be set out as target knowledge in examinations taken by most 16 year olds in England, rather than reserved for advanced, elective courses might be questioned. The argument made here is that if this is the level of treatment expected, it should be consistent with other aspects of the curriculum. This raises the issue of how this 
interpretation fits with a statement such as "reactions of acids with alkalis to produce a salt plus water".

If a secondary student carries out a neutralisation reaction, such as the preparation of sodium chloride from hydrochloric acid and sodium hydroxide solution, then the salient part of the activity is the production of sodium chloride crystals when the solvent is evaporated. Two colourless solutions are mixed without any obvious change occurring (unless indicator is added to one of the reactant solutions), and it is only when the water is allowed (or sometimes encouraged) to evaporate that anything new appears-white solid crystals of sodium chloride, a substance that was not present before the reaction. Although water molecules were formed in the neutralisation process, this is not obvious to an observer, and as the whole system is aqueous it may not even be clear this is sufficient for a reaction (as no new substance is produced which was not present in the reactant solutions).

A criterion at the submicroscopic level sometimes used to distinguish chemical change (i.e., reactions) from physical change is the breaking, and formation, of chemical bonds. The interaction of hydrogen ion and hydroxyl ions to form water molecules certainly meets this criteria, although this process (and its reverse) were already occurring in the reagent solutions as part of the equilibrium by which water molecules dissociate and reform. A new type of bond not present before, the ionic bonding in the $\mathrm{NaCl}$ crystal lattice, only forms as the solvent is removed (when a kind of bond breaking also occurs as hydration of the ions breaks down), and occurs without proton transfer and/or electron transfer and/ or electron sharing. The argument here, then, is not that it is chemically inappropriate to "recognise that aqueous neutralisation reactions can be generalised to hydrogen ions reacting with hydroxide ions to form water", but rather that a level of treatment of neutralisation that (a) only adopts a description at the molecular level and does not consider the nature of chemical reactions at a macroscopic level; and (b) focuses on the production of additional water molecules, and ignores the more salient aspect of the reaction (the production of a salt); does not seem well-judged for the general population of 14-16 year olds subject to the ENC.

\section{Defining chemical reactions}

Another potential interpretation is that the notion of a chemical reaction being offered as target knowledge is one that does not cover these types of processes (processes that I would consider are canonically considered reactions), and that my notion of the canonical concept of chemical reactions is different from that of the anonymous authors of the curriculum model. After all, I have above challenged the assumption that there are unambiguous, readily identifiable, canonical concepts that all chemists might agree on. Therefore I should admit the possibility that I am just in the particular camp of those chemists who consider neutralisation and precipitation as chemical reactions.

So we might ask if there is an explicit definition of chemical reactions in the ENC. After all, in the preceding paragraph I have assumed that I may take "neutralisation reactions" as a kind of "chemical reaction". Usually in chemistry the terms 'reaction' and 'chemical reaction' are used as synonyms, but it is logically possible that in this curriculum model a distinction is being drawn (that is, not all types of reactions are chemical reactions; chemical reactions are one class of reactions). This does not seem very plausible, but if I am claiming different chemists may have different takes on what is considered canonical, then I should not assume I know how others would define terms, and so I should therefore acknowledge this is a logically possible interpretation. 
Commonly, a chemical reaction can be defined as a process where we have different chemical substances before and after the process. This conception does not seem to be explicitly required in the ENC. In chemistry there is a foundational distinction between the wider category of materials and the more exclusive category of substances, which are the primary focus of the discipline. This fundamental distinction is not always well observed in the wording of the ENC. So Y5 students (i.e., 9-10 year olds) should be "taught to... explain that some changes result in the formation of new materials, and that this kind of change is not usually reversible, including changes associated with burning and the action of acid on bicarbonate of soda" (DFE 2015). This appears to be intended to introduce the notion of chemical change (i.e., chemical reactions), so the term 'substance' would be more appropriate here than 'material'. This word choice cannot be explained as a wish to defer introducing 'substance' as a new technical term, as the ENC makes reference to how in the previous school year (Y4, 8-9 year olds) "pupils might work scientifically by ... exploring the effect of temperature on substances [sic] such as chocolate, butter, cream..." (DFE 2015), none of which are actually substances.

The preamble to the KS4 specification includes the statement that "chemistry is the science of the composition, structure, properties and reactions of matter, understood in terms of atoms, atomic particles and the way they are arranged and link together." The term 'atomic particles' is not explained (and again the wording here in the current official curriculum document is unchanged from the 2014 draft), but given the references to electrons elsewhere presumably intends what are more commonly called subatomic particles. There does not seem to be anything closer to a definition of a chemical reaction in the KS4 chemistry content, but there is a definition on the KS3 chemistry content that sets out what should have been studied earlier in secondary school. The students are to be taught about "chemical reactions as the rearrangement of atoms".

The documents setting out the requirements for national examinations refer to substances in many places, but again do not explicitly offer a macroscopic definition of a chemical reaction as involving the formation of new (or different) substances, rather echoing the ENC notion of a reaction (DFE 2015) being understood in terms of an atomic level of description: simply reproducing the statement "Chemistry is the science of the composition, structure, properties and reactions of matter, understood in terms of atoms, atomic particles and the way they are arranged and link together" (Ofqual 2015a, p. 18, b, p. 20).

\section{An atomic ontology}

Now to understand chemical reactions as the rearrangement of atoms is certainly a simplification of canonical chemistry. Such a statement suggests chemistry involves atoms as the basic interacting units of matter and these get moved about into different arrangements in chemical reactions. A more sophisticated model, if still a simplification that would not always apply, would consider atomic kernels or cores (nuclei plus 'inner' shells of electrons) and (valence) electrons are what get rearranged in chemical reactions. In the two classes of chemical reaction I have highlighted there are no atoms being rearranged. In the lead iodide case, lead ions and iodine ions are the entities considered to be interacting in the reaction; in the neutralisation reaction, hydrated hydrogen ions interact with hydroxyl ions, leaving the spectator ions (sodium and chloride ions) in solution, till the solvent evaporates. (And the solvent is molecular, not atomic).

I would suggest that, in general, chemical reactions involve molecules and/or ions, and seldom ever involve reactants in the form of discrete atoms. That seems to be a reasonable 
statement based on the vast catalogue of reactions that have been investigated, even if a common approach in teaching is to think about how compounds come about by considering discrete atoms (Taber 2003). Whether more than a negligible proportion of all the methane molecules that have every existed in the universe have been formed by the direct combination of a lone carbon atom with four discrete hydrogen atoms seems very dubious (under conditions where such atomic species might be common, perhaps in some places in interstellar space, it is unlikely the product molecule would be stable enough to retain its structural integrity) - yet a substantial proportion of teaching treatments found in secondary school textbooks follow just such a scheme.

It may be that as part of a spiral curriculum a model of chemical reactions based on undiscriminated atoms could be a stage of learning that leads to later more sophisticated models. Indeed the KS3 specification (for 11-14 years olds) might well be intended as just such a curricular model, as under the heading 'The particulate nature of matter' the bullet points include "Atoms, elements and compounds" and "a simple (Dalton) atomic model". The phrase "atoms, elements and compounds", without any reference to molecules, seems a little odd, as again elements and compounds are nearly always comprised of molecules and/or ions, rather than discrete atoms. However, this is not the case if we adopt a historical model of the atom along the lines of the now anachronistic "simple (Dalton) atomic model" as this did not fully discriminate atoms and molecules as canonical chemistry does today (Chang 2012), and so in this context 'atom' is meant more generally, and in the phrase "chemical reactions as the rearrangement of atoms", 'atoms' should be interpreted more generically.

That said, it is quite clear from the references to electron donation and the like, that at KS4 (the stage at which this curricular model of three classes of reaction mechanisms is to be taught) students are meant to have progressed beyond using a simple Dalton model and indeed elsewhere in the KS4 content it is specified that students should learn about "a simple model of the atom consisting of the nucleus and electrons, relative atomic mass, electronic charge and isotopes".

It would seem that the three potential interpretations I consider here are all problematic. It is difficult to tally the requirement to teach students that "chemical reactions take place in only three different ways: proton transfer; electron transfer; electron sharing" with two common classes of reactions often taught at this age (precipitation/'double decomposition' reactions and neutralisation reactions). This is especially problematic for the case of neutralisation, as at the point where students are to be taught "chemical reactions take place in only three different ways: proton transfer; electron transfer; electron sharing" they should already have learnt about acid-alkali neutralisation reactions.

\section{An alternative conception of ionic bonding}

I can tentatively offer one further potential interpretation based upon my own experience of teaching, and my research with students at KS4 level and those who had successfully completed examinations at that level studying for what in England is known as Advanced Level (A level) chemistry. When I was discussing a precipitation reaction with one A level college student I was told that when the precipitation occurred an ionic bond was formed because there was electron transfer from the metal atom to the non-metal atom. This surprised me, as the student had already told me about the ions present in the solutions being mixed. The explanation offered was that before the precipitation could occur, the ions in 
the original solutions became neutral atoms by returning donated electrons (i.e., back to their original owners!), which allowed the interacting atoms (as they would then be) to undergo an electron transfer event facilitating ionic bond formation.

From the perspective of canonical chemistry, this seems an obscure scheme, and to unnecessarily complicate matters. If there are charged iodide ions and charged lead ions in close proximity in solution, why not assume they are attracted together rather than that they first undergo a preliminary electron transfer (of electrons from nonmetal ions to metal ions) to give neutral atoms which (somehow being stable enough to exist in solution) then undergo a second electron transfer event to again become ions.

However, from a very common conceptual framework learners develop about ionic bonding (Taber 1997), this convoluted scheme makes some sense. Students at ages 14-16, and even many aged 16-19, commonly consider that an ionic bond is only formed where two atoms have engaged in electron transfer. So, in an $\mathrm{NaCl}$ lattice each ion is (according to this conceptual framework) chemically bonded to one other ion with which it shares a history of electron transfer, and is then attracted to other coordinating ions just by forces (not considered to count as chemical bonding). In this scheme, precipitating ions could only form bonds if they have transferred electrons between them.

Students will commonly draw diagrams to represent ionic bonding that actually show a hypothetical electron transfer event between two discrete atoms, and will consider that to be a necessary condition of ionic bonding such that they will claim that is how the bonding in any sample of sodium chloride formed. Knowing that binary synthesis of $\mathrm{NaCl}$ involves a metal and a molecular substance does not seem to necessarily disrupt this way of thinking, and nor does having actually produced $\mathrm{NaCl}$ themselves by neutralisation and evaporation.

Students holding this alternative conceptual framework for ionic bonding would find no inconsistency between the ENC statement that "chemical reactions take place in only three different ways: proton transfer; electron transfer; electron sharing" and knowledge of precipitation or neutralisation reactions, as these are considered to lead to ionic compounds because of electron transfer between atoms. That is an alternative conceptualisation (alternative to the canonical chemistry) that is found among many learners, yet it is surely not an explanation for the actual inconsistencies in the ENC. That would suggest that ionic bonding being formed by electron transfer (for example the energetically unfavourable transfer of an electron from a sodium atom to a chlorine atom-where the electron affinity is not great enough to provide the ionisation energy needed) is being offered as an official curricular model.

I am not suggesting that is the case, and indeed I sincerely hope this was not the intention of the anonymous authors of the ENC chemistry content. However, the only specific statement about the nature of chemical bonds in the ENC chemistry content is "atoms bond either by transferring electrons from one atom to another or by sharing electrons". This statement was also questioned when the curriculum was published in draft form (Taber 2014). There is no reference to how ions might form bonds with each other, only atoms. Although students are to be taught about "types of chemical bonding: ionic, covalent, and metallic" there is no detail of the treatment of ionic bonding. So even if the ENC model is not intended to imply that ionic bonds are formed by electron transfer between atoms, that would seem to be the only consistent interpretation of the sets of statements included in the document. It is difficult to see what other coherent interpretation of neutralisation reactions can be possible for those required to teach: 
- Defining acids and alkalis in terms of neutralisation reactions.

- Reactions of acids with alkalis to produce a salt plus water.

- Chemical reactions take place in only three different ways: proton transfer; electron transfer; electron sharing.

- Atoms bond either by transferring electrons from one atom to another or by sharing electrons.

\section{Discussion}

I am not able to offer a convincing account of why the statements in the ENC take the form they do. As suggested above, producing a curriculum model requires having a view on (i) what counts as chemical knowledge, on (ii) which elements of that chemical knowledge should be selected for inclusion, and (iii) to what extent the selected knowledge should be simplified to be meaningful for students whilst remaining true enough to the canonical chemistry to be considered authentic knowledge. There are at least two other important considerations that can complicate the process.

Knowledge is highly interconnected (Gilbert and Watts 1983). A chemist's concept of acid, for example, is linked to, and in part depends upon, their concepts of reaction, neutral, $\mathrm{pH}$, solution, proton, compound, etcetera (Taber 2019). So, selecting knowledge by identifying discrete statements can be a little like dissection. It would be possible, for example, to cut out the heart from a small rodent, and claim with some justification that 'this is a heart'. Yet it would not be a heart in the way it was when it was fully connected and integrated into the body. It no longer functions as a heart. It is not possible to understand what is intended by "chemical reactions take place in only three different ways" as part of a curriculum model without also knowing how "chemical reactions" is to be understood within that model. When teachers are asked to base their teaching presentations upon textual representations of curricular models, they are to some degree involved in a hermeneutic endeavour in determining precisely how particular statements are to be understood. So I assume that "atomic particles" (in the phrase "the composition, structure, properties and reactions of matter, understood in terms of atoms, atomic particles and the way they are arranged and link together") meant electrons and nuclei and atomic kernels/cores because this seemed coherent with other statements that also appear in the KS4 content specification. Had, instead, the same statement appeared in the KS3 content specification-where a simple Dalton atomic model was prescribed, and where there is no reference to the concepts 'molecule', 'ion', or 'bond' - I would likely have concluded that "....atoms, atomic particles..." had been used as synonyms.

The related complication is that the curriculum document is a text, and so-just as with a journal paper reporting a chemistry research study-does not contain knowledge, but is rather a representation of someone's understanding. The anonymous authors of the ENC chemistry content had a mental notion of the curricular model they intended to communicate by specifying that school children in England should learn that

"chemical reactions take place in only three different ways:

- proton transfer

- electron transfer

- electron sharing" 
(Or, alternatively, perhaps unbeknown to them, those authors actually held somewhat different curricular models in mind, but they each separately considered this phrasing to effectively represent their own intended model.)

I assume that what was meant by "energy is conserved in chemical reactions so can therefore be neither created nor destroyed" was more along the lines that energy can be neither created nor destroyed and therefore is conserved in chemical reactions (or "energy is conserved in chemical reactions because it can be neither created nor destroyed"). It seems to me that the people chosen to prepare the curriculum specification are more likely to have made a poor choice of expression, or indeed made and then failed to notice a typographic error, rather than to have misunderstood such a basic scientific idea. Yet to come to that provisional conclusion I need to go beyond the text itself, and use my background knowledge to make assumptions about what seems plausible and most likely. My interpretation is partially about the actual text itself, but also depends upon the mental resources I can bring to the text (not only my understanding of scientific concepts, but my expectations and beliefs about the care that would surely be taken by a national government in selecting and supporting the team of curriculum authors) in order to make sense of that text.

However, I do not seem to have sufficient resources to make good sense of the core idea that reactions can only occur by proton transfer and/or electron transfer and/or electron sharing. In relation to neutralisation reactions, I cannot interpret this representation of a typology of reaction mechanisms in a way that is consistent with other statements in the ENC and my own understanding of the chemistry-my beliefs about what should count as canonical chemistry. I have been able to fit this statement with a common alternative conceptual framework often found among students, but if I accept that interpretation then I have to conclude that the people who prepared the ENC chemistry statements understand ionic bonding in terms of electron transfer between atoms, rather than as the mutual forces between ions. This would suggest that those selected as experts to offer an official representation of chemical knowledge deemed suitable for school children in England themselves think of $\mathrm{NaCl}$ as containing molecule-like chemically bonded pairs of ions sharing a history of electron transfer, that are held in a lattice with other similar ion-pairs by forces that do not count as chemical bonding (Taber 1997). That interpretation is consistent with the ENC statements, but leads to the deduction that the ENC for chemistry was entrusted to people who had some rather major flaws in their understanding of chemistry. Alternatively, I could imagine that the authors of the curriculum document are fully aware of the nature of ionic bonding, but think that a presentation based on electron transfer between atoms is good enough (perhaps even an optimal simplification) for learners of this age. If so, that would seem to be a misjudgement as more advanced students find it very difficult to move beyond such a conception of ionic bonding once they have formed it (Taber 2013a).

This study has focused on one small feature of one national curriculum prescription of chemical knowledge. Perhaps other chemists will dismiss my own take on what is canonical knowledge (perhaps most chemists think that ionic bonds in precipitates are formed by electron transfer, and I am just mistaken?) If so, this reinforces the point that in chemistry education we rely on the idea of there being canonical knowledge, and find it problematic when two supposedly qualified people have inconsistent notions of what it is. Perhaps readers of this paper will conclude that they can interpret the statement about the three exclusive ways in which "chemical reactions take place" in a manner which unproblematically includes neutralisation and precipitation reactions. If so that reinforces the point that a text (such as a curriculum document) does not contain knowledge, but is only a representation, necessarily open to interpretation. 
Alternatively, perhaps readers will agree with me that this ENC statement ("chemical reactions take place in only three different ways...") cannot be read to include some canonical examples of types of chemical reaction, and that is not an acceptable representation of the chemistry. If so, then perhaps at one level all this shows is there is a mistake in a government document, supposedly put together by experts, supported by professional civil servants, and published as statutory guidance (i.e., with the force of law) to inform teachers and examination boards on what should be taught and examined. At the time of writing, this mistake (if it is judged to be one) has been allowed to stand for over three years, even though the draft versions had been amended by the Department for Education to correct other examples of what were recognised as errors.

At the very least, this example illustrates how the process of producing curricular models is not straightforward. I would suggest that if we think it is important to teach and examine such abstract ideas as how chemical reactions occur, especially in a curriculum that is imposed on all school children regardless of their personal aptitudes and preferences, there is a responsibility to ensure that what is taught is authentic knowledge. Simplification is necessary, but what is presented should be coherent. If a national government decides that all its children must study "reactions of acids with alkalis to produce a salt plus water" and that they must also be taught an exclusive typology of reaction mechanisms, then there should be a responsibility to make sure the typology can be seen to apply to this group of reactions. Asking children to learn highly abstract ideas that are non-canonical and/or incoherent is an abuse of the government's power to prescribe curriculum.

As well as sequencing material so that more foundational ideas and topics are mastered before those for which they make up prerequisite learning are taught, a spiral curriculum revisits topics at increasing levels of sophistication over time. That requires taking into account both the match between sophistication of treatment and what students of a particular age are ready to learn, and the logic of the discipline that is being represented in the curriculum. One suspects that producing an effective curriculum of this type depends upon a careful iterative process of development involving a large team of disciplinary and educational experts working together to slowly refine drafts that evolve into a document that is both authentic to the science and educationally viable, whilst also being internally coherent. One also suspects that the anonymous authors and editors of the ENC were not provided with the luxury of such a process.

Having acknowledged the scale of the task, I will, by way of recommendations, here just offer a few observations relating to some issues raised in this article. The first concerns the core notion of substance. The substance concept is foundational to chemistry, and so the distinction between materials in general and substances in particular (i.e., elements and compounds) is a critical one (Taber 2012). In principle, if not always readily in practice, materials can be processed (by various physical means) to give one or more pure samples of distinct substances. Clearly there is a moot question regarding when this idea can best be formally introduced, and the level of treatment appropriate. Yet it is important (especially when chemistry in the primary and lower secondary years is often taught by nonspecialists) that any curriculum document should be careful in its language, and (unlike the ENC) restrict the use of 'substance' to refer only to examples of materials that actually are substances. Progression in understanding the substance concept will likely move from activities to separate mixtures to (perhaps some years later) particle models reflecting the distinction, and this progression should be reflected in the curriculum.

This brings me to one of the core ideas in chemistry education: that in teaching chemistry we ask students to be able to work with macroscopic ideas, submicroscopic models, and symbolic representations (Johnstone 1982), and this mutli-levelled 
treatment needs to be introduced carefully to avoid overwhelming learners (Johnstone 2000). Specifically, chemistry involves phenomena that may be observed by students (colour changes; flames; bangs, smells, etc.,), which we first re-describe at the macroscopic level in terms of technical concepts (combustion, oxidation, dissolving, precipitation, etc.), and then often also explain in terms of theoretical entities at the nanoscale (ions, molecules, electrons). Moreover, chemistry has a range of special symbols (e.g., for benzene rings, radicals, transition states, etc.) and, in particular, core symbolic representations for substances and reactions (i.e., chemical formulae and equations) that are usefully ambiguous as they can refer to both the macroscopic descriptions (e.g., a sample of a substance) and the submicroscopic models (e.g., a molecule of that substance) and so can be used in explanations to bridge these two levels (Taber 2013c). A spiral curriculum for teaching chemistry across multiple grades has to offer guidance on progression in relation to this macroscopic-observable/submicroscopic-theoretical/ symbolic-representational 'triplet' (Talanquer 2011).

So the ENC falls down in part because it only defines chemical reactions in terms of the submicroscopic level and ignores the macroscopic account that is a more direct redescription of the phenomena learners can actually experience. Students need to learn that chemical reactions involve changes in the substances present, as well as (and sensibly before) a model of how this is understood at the molecular level. Moreover, whilst at the submicroscopic level it may be appropriate (i.e., it can at least be argued to be appropriate) to initially equate reactions with rearrangements of atoms, a spiral curriculum has to specify how such a description is to be developed when students are expected to progress beyond a generic notion of 'atom' (that actually encompasses molecules and ions, and so is not the ideal term to use) to a more sophisticated model of an atom with an internal structure. A chemical reaction leads to the production of different substances, and this can be understood as a reconfiguration of the atomic cores and associated electrons considered to make up those substances at a submicroscopic scale. (In a neutralisation reaction one such reconfiguration occurs when hydrogen ions and hydroxyl ions form water molecules; but another occurs when solvent molecules are removed and the cations and anions clump together to form a lattice.)

Ignoring the macroscopic level allows one to indeed identify the neutralisation reaction with "hydrogen ions reacting with hydroxide ions to form water" which fits with the idea that a reaction occurs by proton transfer and/or electron transfer and/or electron sharing. Yet, this offers a disconnect with the student's experience of using neutralisation"reactions of acids with alkalis to produce a salt plus water"- to produce a salt. Arguably, the macroscopic notion of a chemical reaction is at least as important, as well as being more directly meaningful to most learners.

Chemistry can be a subtle and sophisticated discipline, where simple definitions and models that clearly apply across the full range of relevant examples may not always be available. Determining when to introduce students to chemical ideas, and at what level, is challenging. So, if a government takes on the challenge of prescribing what should be taught and learnt, then it needs to commit sufficient resources to the task to avoid basic errors, inconsistencies, and statements that cannot be readily interpreted coherently by teachers. In places, at least, the ENC is not fit for purpose.

The processes by which disciplinary knowledge is represented in curriculum, and then in actual teaching practice, and so comes ultimately to be understood by learners, are complex (Taber 2013b, 2019). The chemical knowledge of many young people is shaped by what it is decided they should be taught in school. Getting a curriculum right is therefore both difficult, and important. The school curriculum may seem to be primarily the concern 
of chemistry education specialists, but I would suggest that the chemistry community more generally should be concerned if the subject matter of their discipline is being misrepresented or made to appear incoherent when represented as target knowledge for learners. Perhaps issues of the development and contents of chemistry curricular models deserve more attention, and not just from those chemists who work in chemistry education. Philosophers of chemistry, for example, may offer just the skills of analysis and clarification of concepts, and the focus on logical consistency, that seem to have been missing in the formulation of the curricular model examined in this paper.

Open Access This article is distributed under the terms of the Creative Commons Attribution 4.0 International License (http://creativecommons.org/licenses/by/4.0/), which permits unrestricted use, distribution, and reproduction in any medium, provided you give appropriate credit to the original author(s) and the source, provide a link to the Creative Commons license, and indicate if changes were made.

\section{References}

AQA: GCSE Chemistry (8462) Specification. AQA Education, Manchester (2016)

Ausubel, D.P.: The Acquisition and Retention of Knowledge: a cognitive View. Kluwer Academic Publishers, Dordrecht (2000)

Bernstein, B., Solomon, J.: 'Pedagogy, Identity and the Construction of a Theory of Symbolic Control': Basil Bernstein questioned by Joseph Solomon. Br. J. Sociol. Educ. 20(2), 265-279 (1999). https://doi. org/10.1080/01425699995443

Bhaskar, R.: Epistemology. In: Bynum, W.F., Browne, E.J., Porter, R. (eds.) Macmillan Dictionary of the History of Science, p. 128. The Macmillan Press, London (1981)

Bliss, J.: The relevance of Piaget to research into children's conceptions. In: Black, P.J., Lucas, A.M. (eds.) Children's Informal Ideas in Science, pp. 20-44. Routledge, London (1993)

Bruner, J.S.: The Process of Education. Vintage Books, New York (1960)

Bruner, J.S.: The transactional self. In: Bruner, J., Haste, H. (eds.) Making Sense: The Child's Construction of the World, pp. 81-96. Routledge, London (1987)

Chang, H.: Is Water $\mathrm{H}_{2} \mathrm{O}$ ? Evidence, Realism and Pluralism. Springer, Dordrecht (2012)

Cornbleth, C.: Beyond Hidden Curriculum? Journal of Curriculum Studies 16(1), 29-36 (1984). https://doi. org/10.1080/0022027840160105

DFE: Combined Science: GCSE Subject Content. Department for Education, London (2014a)

DFE: Science key stage 4: June 2014 Draft. Department for Education, London (2014b)

DFE.: National curriculum in England: science programmes of study. Retrieved from https://www.gov.uk/ government/publications/national-curriculum-in-england-science-programmes-of-study/national-curri culum-in-england-science-programmes-of-study (2015). Accessed 15 July 2018

Edexcel: GCSE (9-1) Chemistry Specification, Issue 3 edn. Peasron Education, London (2018)

Eduqas: WJEC Eduqas GCSE in Chemistry Accredited by Ofqual Specification, 3rd edn. WJEC CBAC Ltd., Cardiff (2019)

Eilks, I., Hofstein, A. (eds.): Relevant Chemistry Education: From Theory to Practice. Sense Publishers, Rotterdam (2015)

Gilbert, J.K., Watts, D.M.: Concepts, misconceptions and alternative conceptions: changing perspectives in science education. Studies in Science Education 10(1), 61-98 (1983)

Gilland, T. (ed.): What is Science Education for? Academy of Ideas, London (2006)

Holme, T., Murphy, K.: The ACS exams institute undergraduate chemistry anchoring concepts content map I: general chemistry. J. Chem. Educ. 89(6), 721-723 (2012). https://doi.org/10.1021/ed300050q

Johnstone, A.H.: Macro- and microchemistry. Sch. Sci. Rev. 64(227), 377-379 (1982)

Johnstone, A.H.: Teaching of chemistry-logical or psychological? Chemistry Education: Research and Practice in Europe 1(1), 9-15 (2000)

Key Stage 3 National Strategy: Framework for teaching science: years 7, 8 and 9. Department for Education and Skills, London (2002)

Latour, B.: Science in Action. Harvard University Pressw, Cambridge (1987)

McConnell, M.C.: Teaching about Science, Technology and Society at the secondary school level in the United States An educational dilemma for the 1980s. Studies in Science Education 9(1), 1-32 (1982). https://doi.org/10.1080/03057268208559893 
Medawar, P.B.: Is the scientific paper a fraud? In Medawar P.B. (ed.) The Threat and the Glory, pp. 228233. Harper Collins, New York, (1990). (Reprinted from: The Listener, Volume 70: 12th September, 1963)

Millar, R., Osborne, J.: Beyond 2000: Science Education for the Future. King's College, London (1998)

Mortimer, E.F., El-Hani, C.N.: Conceptual Profiles: A Theory of Teaching and Learning Scientific Concepts, vol. 42. Springer, Berlin (2014)

OCR: Gateway Science Combined Science A. OCR, Cambridge (2019)

Ofqual: GCSE Subject Level Conditions and Requirements for Combined Science. Office of Qualifications and Examinations Regulation, Coventry (2015a)

Ofqual: GCSE Subject Level Conditions and Requirements for Single Science (Biology, Chemistry, Physics). Office of Qualifications and Examinations Regulation, Coventry (2015b)

Palmer, D.: The effect of context on students' reasoning about forces. International Journal of Science Education 19(16), 681-696 (1997). https://doi.org/10.1080/0950069970190605

Piaget, J.: The Principles of Genetic Epistemology (W. Mays, Trans.), (1970/1972). Routledge \& Kegan Paul, London

Popper, K.R.: Objective Knowledge: An Evolutionary Approach, Revised edn. Oxford University Press, Oxford (1979)

Popper, K.R.: The myth of the framework. In: Notturno, M.A. (ed.) The Myth of the Framework: In Defence of Science and Rationality, pp. 33-64. Routledge, Abingdon (1994)

Portelli, J.P.: On defining curriculum. Journal of Curriculum and Supervision 2(4), 354-367 (1987)

Programme for International Student Assessment: PISA Computer-Based Assessment of Student Skills in Science. OECD Publishing, Paris (2010)

QCA: Unit 7F Simple Chemical Reactions. Qualifications and Curriculum Authority, Coventry (2000)

Royal Society of Chemistry: Accreditation of Degree Programmes. Royal Society of Chemistry, Cambridge (2017)

Scerri, E.R.: Transition metal configurations and limitations of the orbital approximation. J. Chem. Educ. 66(6), 481-483 (1989)

Shapin, S.: Why the public ought to understand science-in-the-making. Public Underst. Sci. 1(1), 27-30 (1992)

Shavelson, R.J., Kurpius, A.: Reflections on learning progressions. In: Alonzo, A.C., Gotwals, A.W. (eds.) Learning Progressions in Science: Current Challenges and Future Directions, pp. 13-26. Sense Publishers, Rotterdam (2012)

Shayer, M., Adey, P.: Towards a Science of Science Teaching: Cognitive development and curriculum demand. Heinemann Educational Books, Oxford (1981)

Sikoyo, L.N., Jacklin, H.: Exploring the boundary between school science and everyday knowledge in primary school pedagogic practices. Br. J. Sociol. Educ. 30(6), 713-726 (2009). https://doi. org/10.1080/01425690903235235

Statutory Instrument.: The Education (National Curriculum) (Attainment Targets and Programmes of Study in Science) Order 1989, (1989). HMSO, England

Taber, K.S.: Student understanding of ionic bonding: molecular versus electrostatic thinking? Sch. Sci. Rev. 78(285), 85-95 (1997)

Taber, K.S.: Finding the optimum level of simplification: the case of teaching about heat and temperature. Phys. Educ. 35(5), 320-325 (2000a)

Taber, K.S.: Multiple frameworks?: evidence of manifold conceptions in individual cognitive structure. Int. J. Sci. Educ. 22(4), 399-417 (2000b)

Taber, K.S.: The atom in the chemistry curriculum: fundamental concept, teaching model or epistemological obstacle? Found. Chem. 5(1), 43-84 (2003)

Taber, K.S.: The return of the prodigal sciences. Educ. Chem. 43(5), 144 (2006)

Taber, K.S.: Learning at the symbolic level. In: Gilbert, J.K., Treagust, D.F. (eds.) Multiple Representations in Chemical Education, pp. 75-108. Springer, Dordrecht (2009a)

Taber, K.S.: Progressing Science Education: Constructing the Scientific Research Programme into the Contingent Nature of Learning Science. Springer, Dordrecht (2009b)

Taber, K.S.: Straw men and false dichotomies: overcoming philosophical confusion in chemical education. J. Chem. Educ. 87(5), 552-558 (2010). https://doi.org/10.1021/ed8001623

Taber, K.S.: Key concepts in chemistry. In: Taber, K.S. (ed.) Teaching Secondary Chemistry, 2nd edn, pp. 1-47. Hodder Education, London (2012)

Taber, K.S.: A common core to chemical conceptions: learners' conceptions of chemical stability, change and bonding. In: Tsaparlis, G., Sevian, H. (eds.) Concepts of Matter in Science Education, pp. 391418. Springer, Dordrecht (2013a) 
Taber, K.S.: Modelling Learners and Learning in Science Education: Developing Representations of Concepts, Conceptual Structure and Conceptual Change to Inform Teaching and Research. Springer, Dordrecht (2013b)

Taber, K.S.: Revisiting the chemistry triplet: drawing upon the nature of chemical knowledge and the psychology of learning to inform chemistry education. Chem. Edu. Res. Pract. 14(2), 156-168 (2013c). https://doi.org/10.1039/C3RP00012E

Taber, K.S.: Ignoring research and getting the science wrong. Educationinchemistryblog (2014) http://www. rsc.org/blogs/eic/2014/05/ignoring-research-and-getting-science-wrong. Accessed 6 May 2014

Taber, K.S.: Alternative Conceptions/Frameworks/Misconceptions. In: Gunstone, R. (ed.) Encyclopedia of Science Education, pp. 37-41. Springer, Berlin (2015)

Taber, K.S.: The nature of science and the teaching of gifted learners. In: Taber, K.S., Sumida, M. (eds.) International Perspectives on Science Education for the Gifted: Key issues and challenges, pp. 94-105. Routledge, Abingdon (2016)

Taber, K.S.: Pedagogic Doublethink: Scientific Enquiry and the Construction of Personal Knowledge Under the English National Curriculum for Science. In: Kritt, D.W. (ed.) Constructivist Education in an Age of Accountability, pp. 73-96. Palgrave Macmillan, Cham (2018)

Taber, K.S.: The Nature of the Chemical Concept: Constructing Chemical Knowledge in Teaching and Learning. Royal Society of Chemistry, Cambridge (2019)

Talanquer, V.: Macro, Submicro, and Symbolic: the many faces of the chemistry "triplet". Int. J. Sci. Educ. 33(2), 179-195 (2011). https://doi.org/10.1080/09500690903386435

Thagard, P.: Conceptual Revolutions. Princeton University Press, Oxford (1992)

Zeidler, D.L.: Socioscientific Issues as a Curriculum Emphasis: Theory, research, and practice. In: Lederman, N.G., Abell, S.K. (eds.) Handbook of Research on Science Education, vol. 2, pp. 697-726. Routledge, New York (2014)

Publisher's Note Springer Nature remains neutral with regard to jurisdictional claims in published maps and institutional affiliations. 